\title{
Electric and magnetic field of different transpositions of overhead power line
}

\author{
RAMŪNas DeltuVa, RoBERTAS LuKoČIUS \\ Department of Electrical and Electronic Engineering \\ Kaunas University of Technology \\ Studentu 48-236A, LT-51367 Kaunas, Lithuania \\ e-mail: ramunas.deltuva@gmail.com
}

(Received: 30.12.2016, revised: 11.05.2017)

\begin{abstract}
In Lithuanian and Polish electric power supply systems, the power transmission lines of $400 \mathrm{kV}$ voltage represent one of the most potential sources of electric and magnetic fields generation. The $400 \mathrm{kV}$ double-circuit overhead power transmission line and its surrounding environment were herby described and simulated through Finite Element Method using COMSOL Multiphysic software package. This study includes magnetic and electric field calculations. The study shows that the values of magnetic field strength and electric field strength present in the vicinity of a $400 \mathrm{kV}$ overhead power transmission line tend to exceed limit values established in the Normative. Measurements are suggested to be taken for the purpose of finding maximum values of magnetic and electric field strength. To reduce these values, it is recommended to increase the height of supports, and restrict human personal and economic activities.

Key words: electric and magnetic field strength, linear charge density, electric and magnetic flux density, electric and magnetic field, power line, transposition
\end{abstract}

\section{Introduction}

In recent decades, the increase in electricity demand is observed in Lithuania. Institutions responsible for the electric power transmission in Lithuania and Poland have decided to implement the power link LitPolLink. This link is supposed to interconnect power systems available in Baltic States with those in Western Europe, and contribute to the development of the united European electric power market while increasing the reliability of power supply. With the aim to increase power transmission capacity, the decision was made to install the additional $400 \mathrm{kV}$ AC double-circuit extra high-voltage power transmission line into the LitPolLink.

Recently, issues associated with effects of the $50 \mathrm{~Hz}$ frequency electromagnetic field on population are being analyzed more and more frequently. One of the major problems is how to ensure safe living conditions for population within areas of presence of such electric and magnetic fields. 
Currently, the new Hygiene's Normative HN 104:2011 "Human protection against electromagnetic fields caused by overhead power lines" is valid in the Republic of Lithuania providing that the maximum allowable level of the electric field strength must never exceed $1 \mathrm{kV} / \mathrm{m}$ in a residential environment, and $0.5 \mathrm{kV} / \mathrm{m}$ within residential and public service buildings. The effective values of magnetic field strength must not exceed $32 \mathrm{~A} / \mathrm{m}$ or $40 \mu \mathrm{T}$ (magnetic flux density) in a residential environment, and $16 \mathrm{~A} / \mathrm{m}$ or $20 \mu \mathrm{T}$ (magnetic flux density) within residential and public service buildings. These numerical values must never be exceeded irrespective of the duration of a person's exposure to an electromagnetic field with a frequency of $50 \mathrm{~Hz}$.

In this paper we evaluate the electric and magnetic field of a new power transmission line in respect of safety.

\section{2. $400 \mathrm{kV}$ double-circuit high voltage $\mathrm{AC}$ electric power transmission line}

The length of the $400 \mathrm{kV}$ double-circuit high voltage $\mathrm{AC}$ power line is expected to be approximately $150 \mathrm{~km}$. The direct current (DC) section will be installed at the Alytus transformer substation. After preparing the Lithuanian electric power transmission system for the synchronous operation within the electric power grid of Continental Europe, the direct current section is also supposed to be used for the asynchronous operation of Lithuanian and Belarusian energy systems.

A $400 \mathrm{kV}$ AC double-circuit extra high-voltage power transmission line is studied with the transposition of 6 conductors in the case of long distance distribution with the aim to troubleshoot the voltage drop unbalance problem. Computer-based simulation utilizing the three dimensional finite element method in the time harmonic mode was performed in COMSOL Multiphysics programming environment with graphical representation. The electric field strength and magnetic flux density distribution near the line were investigated. In general, electric field strength of the system depends on an operating voltage level applied to phase conductors. Due to the voltage regulation of the transmission systems, the conductor surface potential does not change to result in remarkable difference of the electric field contours. In the same manner, magnetic field strength of the system significantly depends on the phase currents flowing through the phase conductors. As mentioned, where a normal steady-state operation is assumed, the current does not suddenly change its value. Therefore, both field distributions are quasi-static.

In the AC system, double-circuit transmission lines consist of 6 conductors. Transposition of conductors results in electric and magnetic field distribution that may cause some serious harm to surround the transmission line. From literature, basic electromagnetic theory or image theory [1-9] are widely used for electromagnetic field calculation in high voltage power transmission lines. So far, there is no report on electric and magnetic field calculation in this scope by using Finite Element Method (FEM). Therefore, this method is suitable for solving the problem involving electric and magnetic field effects around the transmission line caused by circular cross-section of high voltage conductors. 


\section{Analysis of electric and magnetic fields from high voltage power transmission line}

The electric and magnetic fields of $50 \mathrm{~Hz}$ at an industrial frequency of $400 \mathrm{kV}$ in a doublecircuit high voltage AC overhead electric power transmission line can be analyzed as two separate fields. $400 \mathrm{kV}$ voltage real value range from $400 \mathrm{kV}$ to $420 \mathrm{kV}$. For calculation we used a value of $420 \mathrm{kV}$.

The essence of the magnetic field investigation by the method of finite elements consists in a finding correct approximation of vector potential components $A_{x}(x, y, z), A_{y}(x, y, z)$ and $A_{z}(x, y, z)$ by basic functions inside of the finite element. In the space without the electric current the magnetic vector potential can be found by the Laplace equation. In the Cartesian coordinate system this equation is:

$$
\frac{\partial^{2} \boldsymbol{A}}{\partial x^{2}}+\frac{\partial^{2} \boldsymbol{A}}{\partial y^{2}}+\frac{\partial^{2} \boldsymbol{A}}{\partial z^{2}}=0 .
$$

The vector-potential of a magnetic field $\boldsymbol{A}(x, y, z)$ can be related with magnetic flux density $\boldsymbol{B}$ and magnetic field strength $\boldsymbol{H}$ by equations:

$$
\begin{gathered}
\boldsymbol{B}=\operatorname{rot} \boldsymbol{A}, \\
\boldsymbol{H}=\boldsymbol{B} / \mu_{0} \mu_{\mathrm{r}},
\end{gathered}
$$

where: $\mu_{\mathrm{r}}$ is the relative permeability, $\mu_{0}=4 \pi \cdot 10^{-7} \mathrm{H} / \mathrm{m}$ is the magnetic constant.

The electric field investigation by the method of finite elements consists in a finding correct approximation of scalar electric potential $V$ by basic functions inside of the finite element. In the space without the electric charges the electric potential can be found by the Laplace equation, too. In the Cartesian coordinate system this equation is as follows:

$$
\frac{\partial^{2} V}{\partial x^{2}}+\frac{\partial^{2} V}{\partial y^{2}}+\frac{\partial^{2} V}{\partial z^{2}}=0 .
$$

The potential $V(x, y, z)$ can be related to electric field strength $\boldsymbol{E}$ and electric flux density $D$ and by equations:

$$
\begin{gathered}
\boldsymbol{E}=-\operatorname{grad} V, \\
\boldsymbol{D}=\varepsilon_{0} \varepsilon_{\mathrm{r}} \boldsymbol{E},
\end{gathered}
$$

where: $\varepsilon_{\mathrm{r}}$ is the relative permittivity, $\varepsilon_{0}=8.85 \cdot 10^{-12} \mathrm{~F} / \mathrm{m}$ is the electric constant.

The functions $V(x, y, z), A_{x}(x, y, z), A_{y}(x, y, z)$ and $A_{z}(x, y, z)$ are continuous coordinate functions with the derivatives of first and second order along each of all three coordinates. All the functions of this type are regarded as harmonious. This paper has considered the system governing by using the time harmonic mode. 


\section{Description of electric power system through FEM}

This paper determines a three-bundled, double-circuit, $400 \mathrm{kV}$ AC power transmission line. Fig. 1 shows the power transmission line with the low-reactance orientation type. Height of conductors shown in the figure is the maximum sag position. The lowest conductors are $\mathrm{C}_{1}$ and $A_{2}$ at the height of $10 \mathrm{~m}$ above the ground surface level [10]. Each phase conductor is of $0.04 \mathrm{~m}$ in diameter. The diameter of the overhead ground wire is $0.015 \mathrm{~m}$.

The height of $400 \mathrm{kV}$ transmission line supports is $54 \mathrm{~m}$. In this particular case, the lower phase wires $\left(\mathrm{C}_{1}\right.$ and $\left.\mathrm{A}_{2}\right)$ (see Fig. 1), including their insulators, should be arranged at the height of at least $26 \mathrm{~m}$ to the ground surface. The sag of the transmission line amounts to $16 \mathrm{~m}$. Adjacent support-bars are spaced by 350 to $550 \mathrm{~m}$.
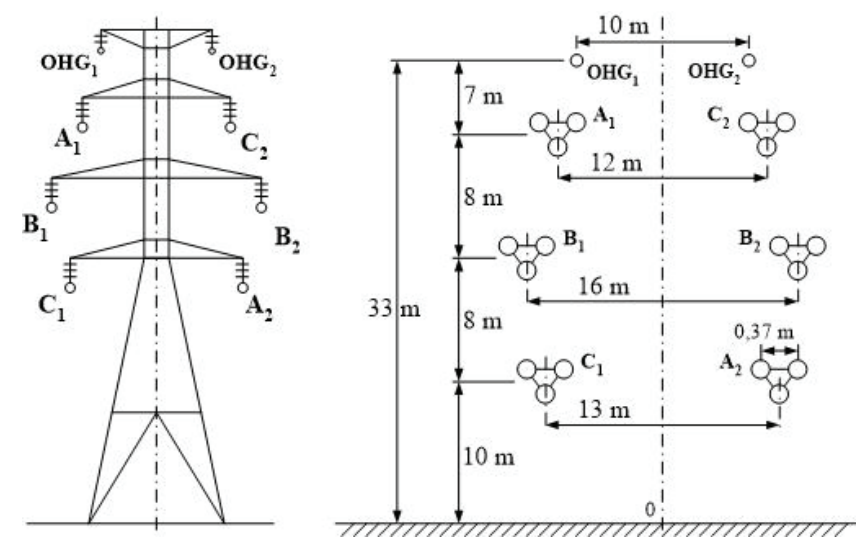

Fig. 1. $400 \mathrm{kV}$ double-circuit, three-bundled transmission line

COMSOL Multiphysics package mesh has the capability of modeling 3D magnetic and electric fields. The geometry, node locations, and the coordinate system for this element are shown in Fig. 2. The element is defined by eight nodes and the material properties. A tetrahedralshaped element may be formed by defining the same node numbers for nodes E, F, G and H, and nodes $\mathrm{C}$ and $\mathrm{D}$. A wedge-shaped element and a pyramid-shaped element may also be formed as shown in Fig. 2.

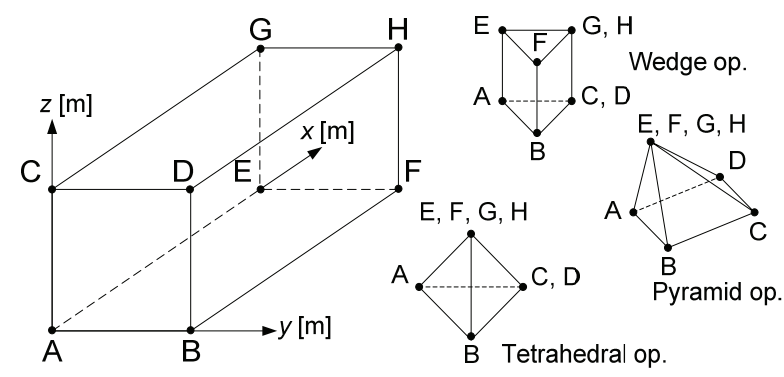

Fig. 2. Geometry of COMSOL Multiphysics 3.5 elements 
Using COMSOL Multiphysics 3.5 for simulation, the finite element mesh was selected to be generated automatically, consequently all the elements were adjusted respectively to the curvature and form of the simulated figure [11-15]. Number of finite elements in the simulation obtained using 3D COMSOL is $n_{\mathrm{fe}}=86649$. Fig. 3 shows the 3D domain of study discretized by using triangular elements or tetrahedrons.

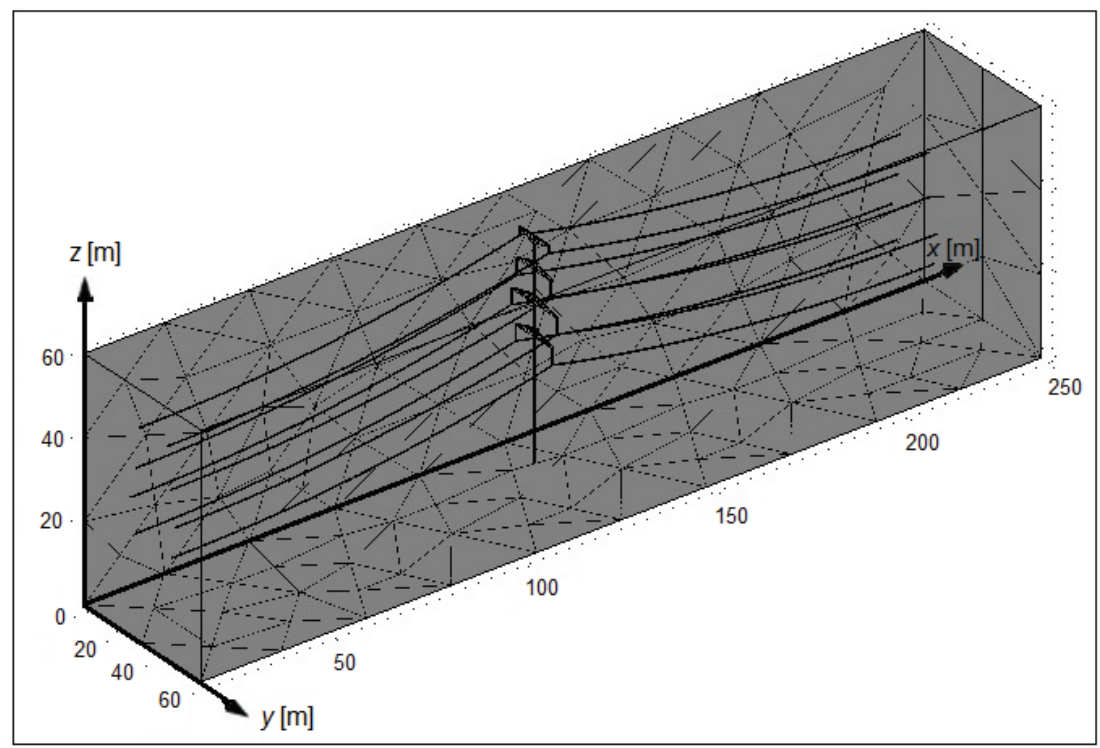

Fig. 3. The FEM discretization for the $400 \mathrm{kV}$ power line

The certainly-element grid is created in a mode of free construction. Therefore final elements are applied in the particular kind in the form of tetrahedrons with four units instead of eight.

In the domains of electric and magnetic fields where a more rapid change in potential and field strength is expected, finer elements are used. Currently, FEM represents one of the most widely used methods of numerical solution to derivative differential equations. Using this method, solutions to differential equations, i.e., values of the potential, are found for nodes in the mesh of the field domain.

\section{$5.400 \mathrm{kV}$ voltage double-circuit power transmission lines simulation parameters and boundary conditions}

In this paper, $400 \mathrm{kV} \mathrm{AC}$, double-circuit, extra high-voltage power transmission lines are studied all 6 groups with 6 types conductors transmission line transposition in case of long distance distribution. There are six types of first group transposition as it is showed in Fig. 4. The boundary conditions applied here are that both electric and magnetic fields at the ground 
level and the OHGW are set as zero. In contrast, the boundary conditions at the conductor surfaces are different.

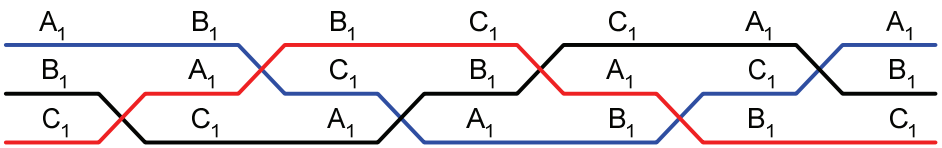

\begin{tabular}{|c|c|c|c|c|c|c|}
\hline $\mathrm{C}_{2}$ & $\mathrm{C}_{2}$ & $\mathrm{~A}_{2}$ & $\mathrm{~A}_{2}$ & $\mathrm{~B}_{2}$ & $\mathrm{~B}_{2}$ & $\mathrm{C}_{2}$ \\
\hline & $\mathrm{A}_{2}$ & $\mathrm{C}_{2}$ & $\mathrm{~B}_{2}$ & $A_{2}$ & $\mathrm{C}_{2}$ & $\mathrm{~B}_{2}$ \\
\hline
\end{tabular}

Fig. 4. Six types of first group transmission lines transposition in case of long distance distribution

However, in this paper, the boundary conditions of both electric and magnetic fields of conductor surfaces in $400 \mathrm{kV}$ power lines are assigned under the maximum loading parameters. $400 \mathrm{kV}$ voltage real value range from $400 \mathrm{kV}$ to $420 \mathrm{kV}$. For simulation we used a value of $420 \mathrm{kV}$.

Magnetic field results are strongly dependent upon the load AC current size. As the effective line current of the three-phase $(\sim 3 \mathrm{ph}$., $50 \mathrm{~Hz}) 420 \mathrm{kV}$ power transmission line is $I_{1}=I_{\mathrm{f}}=2.5 \mathrm{kA}$. The value of the amplitude phase AC current is equal to $I_{\mathrm{mf}}=3.54 \mathrm{kA}$.

Electric field results are dependent upon the load voltage size. As the effective phase voltage of the three-phase $(50 \mathrm{~Hz}) 420 \mathrm{kV}$ power transmission line is $U_{\mathrm{f}}=242 \mathrm{kV}$. The value of the amplitude phase voltage is equal to $U_{\mathrm{mf}}=342 \mathrm{kV}$.

This simulation uses a system frequency of $50 \mathrm{~Hz}$. The power lines are bared conductors of Aluminium Conductor Steel Reinforced (ACSR), the relative permeability $\mu_{\mathrm{r}}=300$, the relative permittivity $\varepsilon_{\mathrm{r}}=3.5$. The magnetic relative permeability and electric relative permittivity of the air $\mu_{\mathrm{r}}=\varepsilon_{\mathrm{r}}=1$.

Electric and magnetic fields lead to energy losses. To minimize these losses, conductors of long flexible current leads must be subject to wire phase transposition. Moreover, transposition of such conductors is also necessary in case positioning and deployment of electrical equipment is complicated in switchgears. Then, special supports for the transposition of overhead power line conductors must be installed at switchgears. As Fig. 4 shows, there may be 36 different transposition schemes of phases of a $400 \mathrm{kV}$ AC double-circuit overhead power lines. Table 1 offers 6 different transposition groups of phase wires with changes in their transposition sequences having particular effects on simulation results.

Table 1. Six groups of transposition

\begin{tabular}{c|c|c|c|c|c}
\hline Group I & Group II & Group III & Group IV & Group V & Group VI \\
\hline $\mathrm{A}_{1}-\mathrm{C}_{2}$ & $\mathrm{~B}_{1}-\mathrm{C}_{2}$ & $\mathrm{~A}_{1}-\mathrm{C}_{2}$ & $\mathrm{C}_{1}-\mathrm{C}_{2}$ & $\mathrm{~B}_{1}-\mathrm{C}_{2}$ & $\mathrm{C}_{1}-\mathrm{C}_{2}$ \\
\hline $\mathrm{B}_{1}-\mathrm{B}_{2}$ & $\mathrm{~A}_{1}-\mathrm{B}_{2}$ & $\mathrm{C}_{1}-\mathrm{B}_{2}$ & $\mathrm{~A}_{1}-\mathrm{B}_{2}$ & $\mathrm{C}_{1}-\mathrm{B}_{2}$ & $\mathrm{~B}_{1}-\mathrm{B}_{2}$ \\
\hline $\mathrm{C}_{1}-\mathrm{A}_{2}$ & $\mathrm{C}_{1}-\mathrm{A}_{2}$ & $\mathrm{~B}_{1}-\mathrm{A}_{2}$ & $\mathrm{~B}_{1}-\mathrm{A}_{2}$ & $\mathrm{~A}_{1}-\mathrm{A}_{2}$ & $\mathrm{~A}_{1}-\mathrm{A}_{2}$ \\
\hline
\end{tabular}




\section{Electric and magnetic fields distributions}

This paper employs COMSOL Multiphysics 3.5 programming to simulate electric field and magnetic field distribution for all 6 groups with 6 types of long distance distributing transposition. The electric field simulated for all six types in group I, that same results for every type can be depicted in Fig. 5.

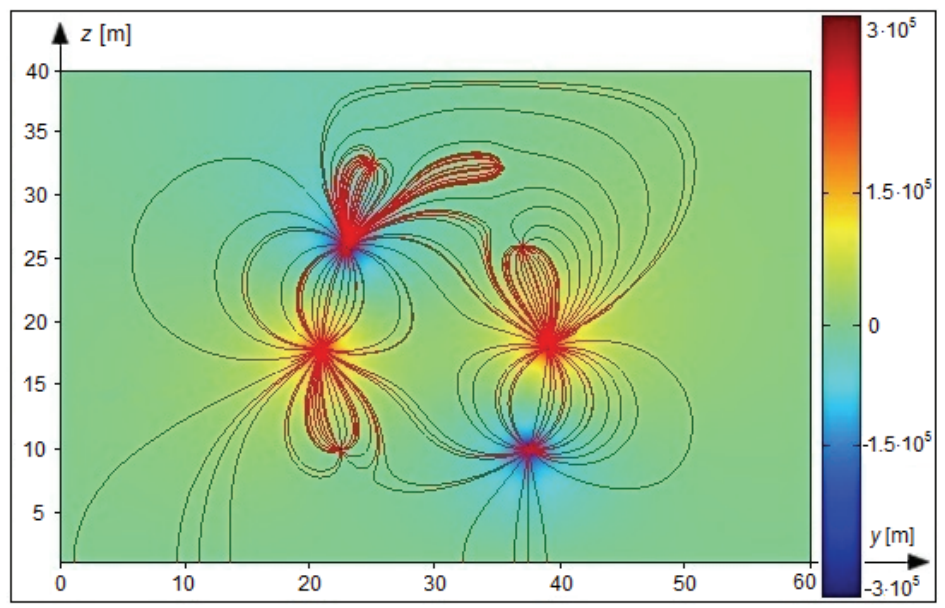

Fig. 5. The distribution of electric field for six types of group I transposition (the lines show electric field strength direction and the colours - the potential)

When consider at some selected positions for more detail, Fig. 6 shows the electric field plot at the height of $1.5 \mathrm{~m}$ above the ground for all six groups that different results every group, respectively.

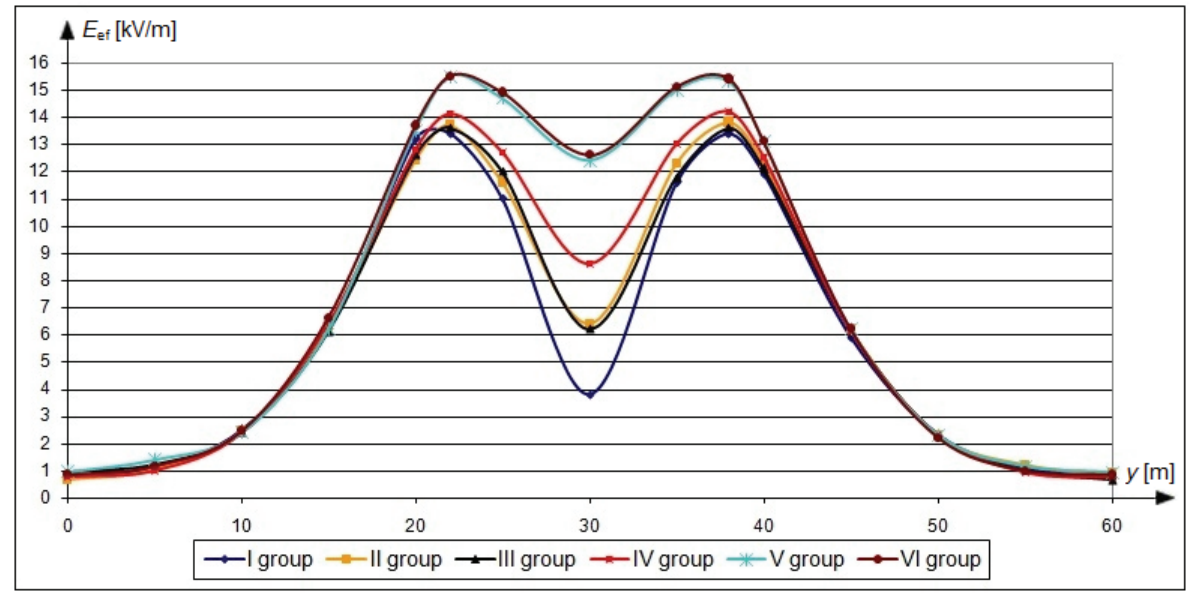

Fig. 6. Distribution of the effective values of electric field strength at $1.5 \mathrm{~m}$ above the ground for all six groups 
Also, simulation results of magnetic field distribution for the six types in group I transposition can be shown in Fig. 7.

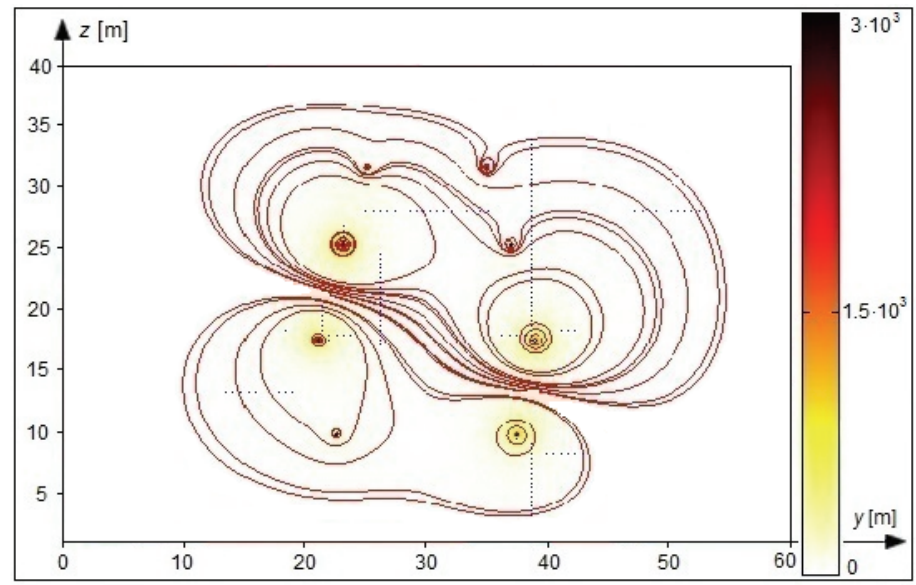

Fig. 7. The distribution of magnetic field for six types of group I transposition (the lines and the colours show magnetic field strength direction)

In addition, Fig. 8 shows the magnetic field plot at the height of $1.5 \mathrm{~m}$ above the ground for all six different groups, respectively.

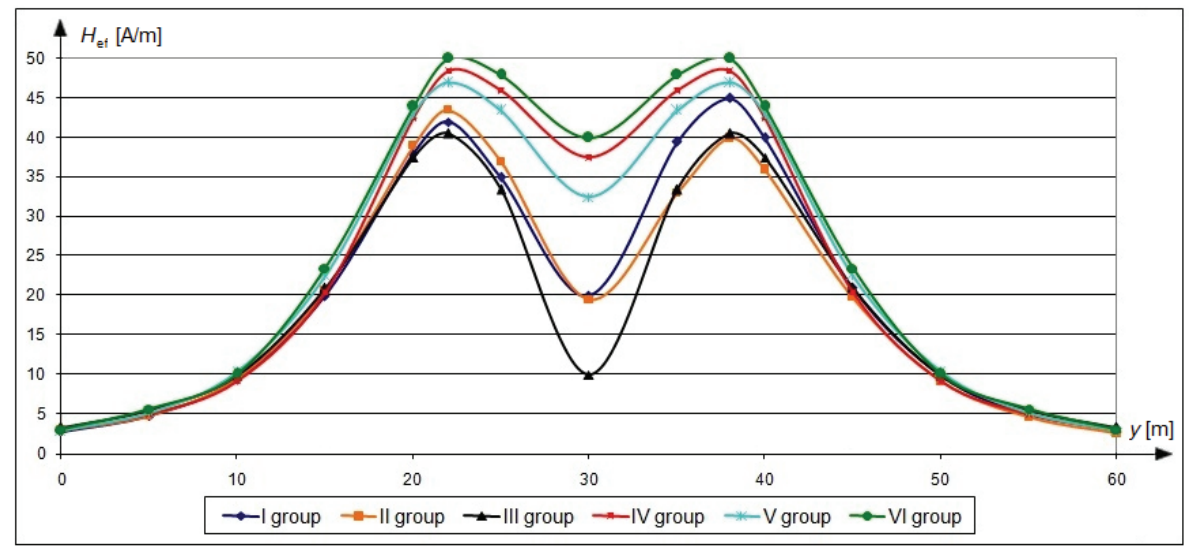

Fig. 8. Distribution of the effective values of magnetic field strength at $1.5 \mathrm{~m}$ above the ground for all six groups

From the simulation results, the all six groups with six types of transmission lines transposition in case of long distance distribution, it will affect changing electric field and magnetic field which surround the transmission line.

Continuous exposure of a person to $50 \mathrm{~Hz}$ frequency EMF leads to occurrence of primary symptoms such as cardiovascular disorders, which in turn increases the probability of cardiovascular diseases, brain stroke, heart attack. Since the occurrence of all the diseases depends 
on the intensity of exposure to an electromagnetic field, the list can be further expanded includeing the following: a gastric ulcer, asthma, pineal gland disruption, intestinal diseases $[16,17]$.

Research of human body exposure to electromagnetic fields showed that the electromagnetic field has effect on the following: 1. Cardiovascular system; hypotonia, bradycardia, reduced ventricular conductance are developed; 2. Immune system. The process of immunegenesis is disturbed, and negative effect is evidenced by impaired cellular immune responsiveness in the T-system of cell-mediated immunity [17]. As a result, it causes leukopenia, lymphocytosis, leucocytosis, monocytosis, pathologic grain of neutrophils, reticulocytosis, thrombocytopenia to develop [18, 19]; 3. Nervous system; leading to functional impairments and disorders of the nervous system. Headache, increased fatigue, memory loss, reduced sexual potency, nausea, dizziness, loss of appetite, feeling of fear and horror, increased sensitivity to light, high blood pressure [17]; 4. Visual system. Impairment of eyes having effect on the cataract formation. A two-sided cataract at posterior wall of the natural lens of the eye, inflammation of ocular tissues, turbidity of the eye lens occur; 5. Coagulation and anticoagulation systems leading to disorders capable of disturbing the process of blood coagulation $[18,19] ;$; 6 . Endocrine system and neurohumoral response. Many parameters (blood morphological and biochemical, functional and biochemical changes in the liver, parameters of metabolism of hydrocarbon and minerals) are associated with disorders of the endocrine system $[18,19] ; 7$. Respiratory and digestive systems. The disorders of functional condition of the respiratory system occur more often as well as functional disorders of the liver and biliary tract; 8. Sexual function. Continuous exposure of the body to EMF leads to reduced activity of pituitary gland, birth abnormalities $[16,17]$.

A magnetic flux density of $40 \mu \mathrm{T}$ is well above the levels that have been associated with childhood leukemia in residential exposure $(0.2$ to $0.4 \mu \mathrm{T})$ and levels that have been associated with brain cancer, breast cancer, and leukemia in occupationally exposed adults (1 to $1.2 \mu \mathrm{T}$ ) [20].

Also, a value of $0.5 \mathrm{kV} / \mathrm{m}$ within residential buildings is exceptionally high as values much lower have been known to adversely affect health. However, since the electric field is unlikely to penetrate building material, this is less of a concern inside buildings and more of a concern for those who spend time outdoors near power lines.

\section{Conclusions}

Simulation results show that effective values of magnetic and electric fields in a sanitary zone of a $400 \mathrm{kV}$ transmission line exceed limit values allowed by the Lithuanian Hygiene's Normative HN 104:2011 "Human protection against electromagnetic fields caused by overhead power lines". This Hygiene's Normative HN 104:2011 has been approved by the European Parliament and Council. The strength of a magnetic field is found to reduce more promptly than that of an electric field. 
Persons residing or undertaking agricultural activities in the sanitary protection zones of a $400 \mathrm{kV}$ double-circuit power transmission line risk to be exposed to an unallowable level of an electromagnetic field. Any personal or economic activities must be forbidden and prevented within distance of at least $50 \mathrm{~m}$ to a $400 \mathrm{kV}$ double-circuit power transmission line. For these reasons, an electromagnetic field in these areas must be reduced by installing higher supports.

This paper has studied electric and magnetic field distribution resulting from all six groups with six types long distance distributing transposition. As a result, the impact from simulation of six groups long distance distributing transposition will effect changing of electric field and magnetic field which surround the transmission line.

While the maximum allowable levels of an electric and magnetic field in the Republic of Lithuania are limited by the Lithuanian Hygiene's Normative HN 104:2011, there is scientific evidence that much lower electric and magnetic field strengths are associated with various types of cancers, the most common of which are leukemia, brain tumours and breast cancer among both men and women occupationally exposed to AC EMFs. Therefore, the limit of $50 \mathrm{~m}$ from $400 \mathrm{kV}$ double-circuit power transmission lines based on the Lithuanian Hygiene's Normative values restricting personal or economic activity from power lines may need to be extended as a precautionary approach.

\section{References}

[1] Olsen R.G., Deno D., Magnetic fields from electric power lines theory and comparison to measurements, IEEE Transactions on Power Delivery, vol. 3, no. 4, pp. 2127-2136 (1998).

[2] Crowley J.M., Fundamentals of Applied Electrostatics, Laplacian Press (1999).

[3] Havas M., Intensity of electric and magnetic fields from power lines within the business district of 60 Ontario communities, The Science of the Total Environment, vol. 298, no. 1, pp. 183-206 (2002).

[4] Safigianni A.S., Tsompanidou Ch.G., Measurements of electric and magnetic fields due to the operation of indoor power distribution substations, IEEE Transactions on Power Delivery, vol. 20 , no. 3, pp. 1800-1805 (2005).

[5] Jin J.-M., Theory and Computation of Electromagnetic Fields, IEEE Press (2010).

[6] Nicolaou Ch.P., Papadakis A.P., Razis P.A., Kyriacou G.A., Sahalos J.N., Measurements and predictions of electric and magnetic fields from power lines, Electric Power Systems Research, vol. 81, no. 5, pp. 1107-1116 (2011).

[7] Dezelak K., Jakl F., Stumberger G., Arrangements of overhead power line phase conductors obtained by Differential Evolution, Electric Power Systems Research, vol. 81, no. 12, pp. 2164-2170 (2011).

[8] Deltuva R., Virbalis A.J., Žebrauskas S., Analysis of electric field in $330 \mathrm{kV}$ overhead transmission line, Proceedings of International Conference Electrical and Control Technologies, Kaunas, Lithuania, pp. 255-259 (2011).

[9] Alipio R.S., Schroeder M.A.O., Afonso M.M., Oliveira T.A.S., Assis S.C., Electric fields of grounding electrodes with frequency dependent soil parameters, Electric Power Systems Research, vol. 83, no. 1, pp. 220-226 (2012).

[10] Deksnys R., Grèblikas P., Rutkauskas M., Rules for the Installation of Electrical Units, Vilnius: Energetics Press (2000).

[11] Silvester P.P., Ferrari R.L., Finite Elements for Electrical Engineers (3rd edition), Cambridge University Press (1996).

[12] Sadiku M.N.O., Numerical Techniques in Electromagnetics, CRC Press (2001). 
[13] Jin J.-M., The Finite Element Method in Electromagnetics (3rd edition), Wiley-IEEE Press (2014).

[14] Deltuva R., Virbalis J.A., Gečys S., Electric and Magnetic Fields of the High Voltage Autotransformer, Electronics and Electrical Engineering, vol. 10, no. 106, pp. 9-12 (2010).

[15] Schroeder M.A.O., Afonso M.M., Oliveira T.A.S., Assis S.C., Computer Analysis of Electromagnetic Transients in Grounding Systems Considering Variation of Soil Parameters with Frequency, Journal of Electromagnetic Analysis and Applications, vol. 4, no. 12, pp. 475-480 (2012).

[16] Harakawa S., Nedachi T., Hori T., Takahashi K., Tochio K., Inoue N., Effect of electric field in conditioned aversion response, J Vet Med Sci, vol. 70, no. 6, pp. 611-613 (2008).

[17] Coskun O., Comlekci S., Effect of ELF electric field on some on biochemistry characters in the rat serum, J Vet Med Sci, Toxicol Ind Health, vol. 27, no. 4, pp. 329-333 (2011).

[18] Tynes T., Reitan J.B., Andersen A., Incidence of cancer among workers in Norwegian hydroelectric power companies, Scandinavian Journal of Work, Environment \& Health, vol. 20, no. 5, pp. 39-44 (1994).

[19] Halliwell B., Gutteridge J., Free radicals in biology and medicine (4th edition), Oxford University Press (2007).

[20] Lee J.M., Pierce K.S., Spiering C.A., Electrical and Biological Effects of Transmission Lines, Bonneville Power Administration (1996). 